\title{
PRECIFICAÇÃO ESTRATÉGICA NO SETOR AÉREO NO BRASIL: O ESTUDO DE CASO DO PROCESSO DE FORMAÇÃO DE PREÇOS DE PASSAGENS AÉREAS EM UMA EMPRESA DE PEQUENO PORTE NO BRASIL
}

\author{
OLIVEIRA, Jorge Henrique Caldeira de ${ }^{1}$ \\ OLIVEIRA, Thiago ${ }^{2}$ \\ GRANDE, Márcia Mazzeo ${ }^{3}$
}

\begin{abstract}
RESUMO: O mercado de aviação doméstico passou por transformações drásticas na última década. Atualmente, grande parte das empresas demonstram dificuldades em apresentar resultados financeiros positivos, apesar de um maior número de passageiros. Parte desses resultados pode ser explicado pela tarifa. O processo de formação de preço no setor aéreo é importante e complexo, pelo fato de o mercado ser extremamente dinâmico e sujeito a inúmeras variáveis. O preço não é apenas o que o consumidor paga na hora da compra: ele é a ponta de um trabalho muito mais estratégico, que envolve desde posicionamento até estratégias de mercado. O objetivo do trabalho é analisar todo o processo de formação de preço em uma companhia aérea de pequeno porte, os modelos utilizados, as alternativas e as principais vantagens e desvantagens. Foi feita uma pesquisa bibliográfica sobre o tema precificação em um contexto mais amplo, passando a uma pesquisa de precificação em companhias aéreas. Foram levantadas informações atuais do mercado de aviação brasileiro junto a uma pesquisa exploratória e descritiva, com entrevistas aos diretores de uma empresa regional de pequeno porte de aviação civil. A análise dos resultados mostrou que é comum a utilização da ferramenta Yield Management (também chamado Revenue Management) como base de formação de preço e que a determinação do preço final é feita principalmente baseando-se na concorrência e na tentativa de extrair o excedente do consumidor dos passageiros.
\end{abstract}

Palavra-Chave: Precificação. Gestão de receitas. Mercado de Aviação.

SUMMARY: The domestic aviation market has undergone drastic changes over the last decade. Nowadays, most Brazilian companies show difficulties in providing positive financial results, despite the larger number of passengers. Part of these results can be explained by the tickets fare. The process of fare formation in the airline industry is important and complex, because the market is extremely dynamic and under the influence of several variables. The price is not only what the consumer pays at the time of purchase: it is the beginning of a much more strategic work, which involves everything, from marketing positioning to market strategies. The purpose of this study is to analyze the whole process of price formation in a small airline company, the models used, the alternatives and the main advantages and disadvantages. In the first part it is presented an extensive literature on the pricing issue in a broader context, moving later to a research of pricing in airlines. At the end, it is presented information's about the current Brazilian aviation market, along an exploratory and descriptive research. The results make clear that companies use the Yield Management or Revenue Management as a tool for pricing and in sectors where competition exists, the determination of the final price is made primarily based on competition.

Keyword: Pricing. Financial management. Aviation market.

\section{INTRODUÇÃO}

O mercado de aviação civil no Brasil está entre os que têm maior perspectiva de crescimento no mundo, com projeções de expressivos investimentos públicos e privados até 2020. Segundo a Associação Brasileira das Empresas Aéreas (ABEAR, 2012), o número de passageiros das companhias aéreas no Brasil, que em 2012 foi de 101,4 milhões, passará a ter cerca de 200 milhões em 2020. Estes números

\footnotetext{
${ }^{1}$ Departamento de Administração. Área de Estratégia - FEARP/Universidade de São Paulo

${ }^{2}$ Graduado pela FEARP/USP

${ }^{3}$ Departamento de Administração. Área de Planejamento, Projeto e Controle de Sistemas de Produção FEARP/Universidade de São Paulo.
} 
serão impulsionados pelos eventos esportivos programados para o país, mas também estimulados por melhores expectativas econômicas com aumento da renda da população (ANAC, 2013).

Em um país de proporções continentais, como o Brasil, a importância de um setor aéreo bem desenvolvido é notória. Apesar desta importância, o mercado brasileiro é oligopolizado. Existe uma concentração de participação em grandes empresas do setor, como se pode visualizar na Figura 1. Nesta figura, evidencia-se a participação elevada de apenas duas empresas, que juntas, concentram 75,5\% do transporte de passageiros civis no país. A própria ANAC já alertou que esta situação não é recente, representando um padrão histórico, sendo que a terceira maior empresa do setor nunca representou mais de $20 \%$ de participação de mercado (ANAC, 2013).

Figura 1: Participação das empresas no mercado doméstico em 2013

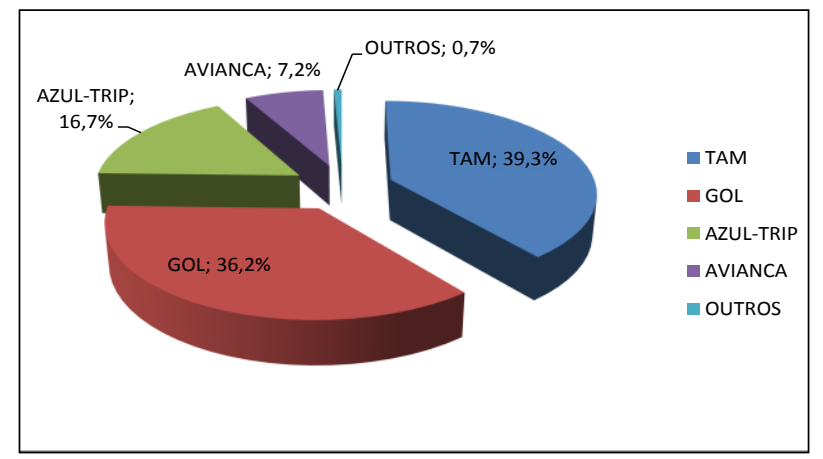

Fonte: ANAC (2013)

A demanda de passageiros pelo Brasil não é bem distribuída, sendo altamente concentrada no sul e sudeste. Os três principais aeroportos do país, em número de passageiros são em ordem: Cumbica, Congonhas e Brasília. Enquanto o sudeste representa o maior mercado aéreo do país e rotas dos principais voos nacionais e internacionais, Brasília se destaca por ser um hub entre as cidades de todo o país, conectando o Brasil de norte a sul (ANAC, 2010; ANAC, 2011).

É nesse contexto de difícil competição oligopolizada e mal distribuída que pequenas empresas devem tomar decisões de precificação. Não tendo acesso aos grandes aeroportos, elas ainda ficam restritas aos aeroportos de localidades menores, com menor demanda. O processo de formação de preço no setor aéreo é complexo e muito dificultado pelas características estruturais supracitadas. Este artigo se propõe a compreender melhor como uma pequena empresa aérea regional no Brasil analisa e decide a precificação, buscando a sobrevivência e lucratividade.

\section{PRECIFICAÇÃo}

O preço é um dos componentes do maketing mix e possui, segundo Kotler (2000), características intrínsecas que o torna singular, devendo ser muito bem estudado e sincronizado com toda a estratégia de marketing, o planejamento estratégico, a administração financeira, entre outras áreas fundamentais da administração. Entre estas características está o fato do preço ser o único componente do mix de marketing que gera receita, além do que é também o mais flexível na maior parte dos segmentos econômicos, , podendo ser alterado rapidamente para se ajustar às mudanças no ambiente de competição da empresa.

A formação tem papel estratégico para as empresas: deve-se buscar uma postura pró-ativa às frente ao mercado, e não simplesmente reagir aos acontecimentos do ambiente de negócios da empresa. 
Assim, o preço é um aspecto influenciador Nagle e Holden (2005) lembram que o apreçamento estratégico, ou princing, também demanda por parte da alta administração da empresa coordenação interna entre as áreas de marketing, finanças, recursos humanos e operações. Ressalta-se a o preço é um aspecto influenciador em todos os níveis estratégicos de decisão (MINTZBERG; QUINN, 2001). Bernardi (2010) aponta que o preço é um fator decisivo para a decisão de compra.

Assim, segundo Kotler e Keller (2006), para se estabelecer o preço final devem ser levados em consideração o objetivo estratégico da empresa, o público-alvo, posição competitiva, custos, canal de venda e ciclo de vida do bem, leis governamentais e grau de competição do setor, entre outras variáveis.

Para Santos (2005), os preços de venda devem levar em consideração: demanda do produto, poder financeiro dos clientes, qualidade do produto, existência de produtos substitutos, legislação, estrutura de custos e despesas da empresa, investimento total no produto e os objetivos gerais da organização.

A formação correta dos preços de venda deve considerar a maximização do lucro, a maximização do faturamento, garantir o crescimento das vendas, , maximizar a capacidade produtiva (ASSEF, 1997; BERNARDI, 2010),

Horngren, Datar e Foster (2004) advogam que as três grandes variáveis que influenciam o processo de formação de preços são: clientes, concorrentes e custos (tabela 1).

Tabela 1: Variáveis que impactam na formação de preços

\begin{tabular}{cc}
\hline VARIÁVEL & INFLUÊNCIA \\
\hline CLIENTES & EXTERNA \\
CONCORRENTES & EXTERNA \\
CUSTOS & INTERNA \\
\hline
\end{tabular}

Fonte: Elaborado pelo autor com base em Horngren, Datar e Foster (2004)

Ou seja, há formação de preço de contemplar tanto fatores internos quando externos à organização. Ou seja: os fatores internos, baseados em custos, devem considerar que as receitas devem cobrir os custos operacionais; já os fatores externos (cliente e concorrentes) consideram que as decisões sobre a formação do preço também recaem sobre a percepção de valor proposta pelo mercado (COELHO, 2009). A importância da precificação para a maximização de receitas é crucial também para as companhias aéreas. Como os serviços de transporte aéreo são perecíveis (um assento vazio é irrecuperável) e a competitividade no setor é muito elevada, os preços das passagens influenciam de forma direta os resultados (AVLONITIS; INDOUNAS, 2007).

Outra característica da precificação é sua flexibilidade devido a possibilidade de ser alterado com agilidade. Não obstante ser considerado uma das maiores qualidades do preço, a flexibilidade talvez seja também um dos maiores problemas para as empresas, visto que os preços dos concorrentes também são dinâmicos e mudam a todo o momento (LOVELOCK, 1996; BAKOS, 1997; KURTZ e CLOW, 1998).

\subsection{Algumas das principais formas de precificação}

A formação de preços de venda de ponto de vista interno pode se resumir a análise de custos e despesas da organização. Passarelli e Bomfim (2008) afirmam que a precificação baseada em custos e despesas é a maneira mais utilizada na área comercial. Quanto mais baixo for o custo, maior será a capacidade de fornecimento da organização.

Custos são gastos relacionados diretamente a produção e comercialização do produto. Os custos 
são gastos intrinsicamente relacionados com o valor pago ao fornecedor e demais fatores ligados a compra da mercadoria, além dos tributos. Despesas representam os gastos ligados as atividades operacionais da loja nas áreas de administração, finanças e vendas. As despesas podem ser classificadas como aquelas que não são diretamente ligadas a compra e produção do bem ou serviço, mas sim a estrutura necessária para a comercialização (WERNKE, 2011). Uma questão importante que se apresenta aqui é o método de apropriação de custos, que deve ser feita de acordo com as metodologias existentes, cabendo ao gestor avaliar qual metodologia empregar em função da natureza da atividade econômica da empresa (MARTINS, 2008).

Existem também técnicas que se baseiam em características de mercado, externas à empresa, como a demanda, gostos de clientes, concorrentes, entre outras. As técnicas de precificação que consideram fatores externos para determinação do preço final visam aumentar a lucratividade em relação às técnicas baseadas em custos. Sartori (2004) comenta que a precificação pela concorrência se baseia nos preços que os concorrentes cobram pelo mesmo produto. Dessa forma, conforme a estratégia da empresa, o produto pode ser precificado acima, abaixo ou no mesmo patamar que os concorrentes. Já Hinterhuber (2010) diz que a fonte primária de informação das técnicas de precificação baseadas em fatores externos são os preços dos concorrentes. A seguir estarão detalhadas algumas das principais técnicas de precificação, apesar de existirem ainda inúmeras outras disponíveis com menor frequência de uso.

\subsubsection{Mark-up}

Mark-up é uma das técnicas mais comuns que se utilizam dos custos. Traduzindo-se do inglês para o português, mark-up significa remarcar para cima (BRAGA, 2008). Segundo Mendes (2009), "pela política de mark-up, o preço de venda de um produto é determinado pela adição de um percentual geralmente fixo, mas que pode ser variável - sobre o custo unitário de produção ou sobre o preço de compra, nos casos de revenda". Uma de suas maiores vantagens é que o preço final pode facilmente ser alterado conforme necessidade. Passarelli e Bomfim (2008) afirmam que essa técnica extensamente utilizada devido a sua facilidade. Para Kotler (2000), essa técnica é muito comum pois é muito mais fácil mensurar custos de que demanda e além disso as pessoas acreditam que determinar preços conforme custos é mais justo.

Motta (2000) define matematicamente o mark-up como:

$$
\mathrm{P}=\sum_{i=0}^{n} \mathrm{Ci} . \mathrm{Zc}
$$

Onde:

P- é o preço unitário de venda

Ci- são os custos

Zc- é o mark-up

Uma das principais vantagens da técnica do mark-up é que é um método simples e sua adequação pode ser feita rapidamente. Prado (2009) comenta que o maior problema desse método é o fato de ele não levar em consideração variáveis importantes como demanda, concorrência e valor percebido.

\subsubsection{Valor percebido}

Existem várias técnicas baseadas no valor percebido dos clientes, mas o objetivo é sempre o 
mesmo: extrair o máximo de lucratividade de um cliente. "Um número crescente de empresas baseia seus preços no valor percebido pelo cliente" (KOTLER, 2000). Prado (2009) afirma que o método de valor percebido considera diversos elementos que compõem o valor final para o consumidor, como desempenho, marca e confiabilidade do produto. Sartori (2004) afirma que o método do valor percebido pode ser definido como uma comparação entre o que os compradores esperam e o que de fato existe. Nesse tipo de precificação, é fundamental que a empresa posicione o produto de forma clara. Nagel e Holden (2005) comentam que esse tipo de precificação deve envolver estratégias de marketing que criem valor ao produto.

A empresa pensa o produto a partir da sua qualidade e do seu valor, não levando em conta variáveis internas, como custo. Esse tipo de avaliação externa pode levar a organização a melhorar seus produtos e processos tendo em vista geração de valor aos clientes finais.

Apesar disso, Hinterhuber (2010) ressalta que muitas vezes os dados para avaliação do valor percebido são difíceis de se obter e de serem interpretados. A empresa deve conseguir convencer o consumidor sobre o preço que está sendo cobrado por aquele produto. Outro ponto que pode ser considerado negativo é o fato de muitas vezes existir resistência por parte dos executivos a diminuírem os preços mesmo quando está claro que o valor percebido tenha diminuído (ZORNIG, 2010).

\subsection{Revenue management: a principal forma de precificação no setor aéreo}

A técnica de precificação chamada Revenue Management (RM) é a principal forma de precificação no setor aéreo, segundo os entrevistados e se baseia na técnica descrita no item 2.1.2 do Valor Percebido, ainda que acrescente outras variáveis e também tenha uma volatilidade de precificação bem diferente do Valor Percebido tradicional. O RM é o mais importante para o setor aéreo devido sua ampla utilização, sendo o sistema de formação de preços predominante nas empresas aéreas devido a sua capacidade de extrair mais receitas e se adequar ao mercado (DUNLEAVY; WESTERMANN, 2005; CHIANG; CHEN; XU, 2006).

O RM (também chamado Yield Management no setor aéreo) é utilizado principalmente no setor de serviços, como em empresas aéreas ou em hotéis, quando os recursos disponibilizados são perecíveis (NETESSINE, 2002). A aplicação das técnicas de RM possibilita às empresas aéreas o gerenciamento de diversas classes de tarifas para milhares de voos diários O principal objetivo do RM é conseguir maximizar as receitas dada uma determinada demanda. Para que exista condições de aplicação do RM são necessários: heterogeneidade dos clientes, demanda variável, produção inflexível e infraestrutura de dados e informações (TALLURY; RYZIN, 2004).

O RM objetiva capturar o preço de reserva dos passageiros. O preço de reserva é o valor máximo que determinado cliente está disposto a pagar. Se o melhor preço oferecido estiver abaixo do preço de reserva ele, obviamente, pagará este preço ao invés do valor máximo (MANKIW, 2012). Assim, o RM objetiva extrair o máximo do preço de reserva (ou excedente do consumidor) de cada passageiro, levando em conta que diferenças de períodos de compra, objetivos da viagem, dias e horários de voos, entre outros, influenciam o preço de reserva de cada passageiro individualmente.

\section{METODOLOGIA DA PESQUISA}

A estratégia de pesquisa adotada foi o estudo de caso. Para Yin (2001) um estudo de caso pode 
ser definido como uma investigação empírica de um fenômeno contemporâneo dentro da realidade do seu contexto, principalmente quando não está muito bem definido os limites entre o fenômeno abordado pela pesquisa e o contexto. Os problemas os quais estudos experimentais não podem ser feitos ou quando os estudos quantitativos não conseguem descrever corretamente os fenômenos estudados são aqueles enquadrados pela natureza do estudo de caso, que envolve a observação e questionamento. $\mathrm{O}$ estudo de caso é adequado no caso em que as perguntas do questionário da pesquisa são do tipo "como" e "por que", e nas quais o pesquisador não tenha controle absoluto da situação, que por sua natureza, esteja dentro de contextos sociais e com alto grau de complexidade (YIN, 2001). É exatamente este o contexto do presente estudo, dado que analisar precificação resulta em identificar diversas nuances de tomada de decisões que são difíceis de serem captadas por estudos quantitativos.

Ludke e André (1986) afirmam que o interesse em um estudo de caso é em razão daquilo que ele tem de único, de particular, mesmo que após as conclusões fiquem evidentes semelhanças com outros casos já conhecidos ou situações. $\mathrm{O}$ instrumento de coleta de dados utilizado foi a entrevista semiestruturada. Foram realizadas 2 entrevistas : uma com o gerente de precificação da companhia aérea e outra com o analista de precificação da empresa. A realização de entrevistas semi-estruturadas permitiu maior liberdade de respostas dos entrevistados.

As variáveis consideradas foram: objetivos da precificação; importância da precificação, estratégia de preço da empresa; competitividade do setor; influência da qualidade dos produtos/serviços nas decisões de preço; os pontos fortes e fracos, as ameaças e as oportunidades para a empresa; tipos de precificação utilizados pela empresa; mecanismos de mudanças de preços de última hora; vantagens e desvantagens do Revenue Management. A partir das respostas obtidas foi possível estabelecer um quadro do os pontos fortes e fracos da empresa, bem como o processo de precificação da empresa estuda. A seguir, são apresentados os resultados do estudo de caso.

\section{ESTUDO DE CASO}

O estudo de caso aqui apresentado foi realizado na Passaredo Linhas Aéreas, uma companhia aérea regional, de pequeno porte, com sede em Ribeirão Preto, no estado de São Paulo. A empresa foi fundada em 1995, com uma frota de três Embraer Brasília. Em 2002 a empresa interrompeu as atividades e voltou somente em 2004, com novos jatos Embraer 145. Após sucessivos aumentos no custo do combustível, a empresa reviu sua estratégia e iniciou um ousado programa de troca da frota, devolvendo todos os aviões do modelo EMB-145 e incorporando a frota seis aeronaves ATR 72. Esses aparelhos são mais lentos (velocidade média mais baixas que os jatos), porém oferecem excelente resultado devido ao baixo consumo de combustível e qualidade operacional.

\subsection{Análise S.W.O.T da Passaredo}

Um dos pontos fortes principais da empresa é a velocidade da tomada de decisões e de implementação das medidas decididas. Por se tratar de uma empresa de pequeno porte e os gestores estarem muito próximos, eventuais problemas são discutidos ou novas medidas são implementados rapidamente se for comparar com as empresas de grande porte do mesmo setor. Essa vantagem pode permitir ao setor de precificação, por exemplo, responder rapidamente a uma promoção de outra outra aérea concorrente.

Outro ponto importante é a identificação dos colaboradores com a empresa. Por ser sediada no interior e empregar mão-de-obra local, investindo em funcionários que cresceram junto a empresa, a 
rotatividade é baixa e o comprometimento relativamente alto. Soma-se isso ao custo baixo da mão-deobra, caso comparado as concorrentes localizadas em regiões metropolitanas maiores, como na Grande São Paulo por exemplo.

A escolha de utilização de turbos hélices ATR 72 também trouxe à empresa uma grande vantagem. Esses aviões são econômicos e oferecem um excelente resultado quando levados em conta custo-benefício, principalmente em rotas regionais (até 500km).

Os pontos fracos mapeados foram: escassez de mão-de-obra qualificada na região de Ribeirão Preto, principalmente em áreas específicas (como Revenue), a pequena escala da empresa que acaba por diminuir o rateio dos custos fixos entre os passageiros, a inexistência de um programa de fidelidade em um mercado extremamente competitivo, a volatilidade da malha em razão da mudança dos aviões e inviabilidade econômica de algumas rotas e finalmente, a desvantagem da empresa em rotas de longo percurso.

Em relação as oportunidades, identifica-se um crescimento da classe média no país, atraindo novos passageiros e gerando crescimento para o mercado. Soma-se a isso o recém-divulgado plano do governo de incentivo aos voos regionais no país, possivelmente através de subsídios e melhoria nos aeroportos em cidades médias e pequenas (KAKINOFF, 2013).

Grande concorrência e entrada de novos players são fatores de atenção. O crescimento da Azul, uma empresa muito capitalizada, e os boatos sobre o interesse de empresas estrangeiras em operar no Brasil são possíveis ameaças as já apertadas margens operacionais. O custo alto do querosene de aviação aliado à volatilidade do câmbio podem dificultar ainda mais a viabilidade financeira de diversas rotas, criando grande volatilidade nas margens de lucro de todo setor aéreo e com impacto particularmente perigoso para pequenas empresas como esta.

$\mathrm{Na}$ entrevista os gestores da empresa explicaram que "as companhias sofrem atualmente pressões de todos os lados. Sofremos pressão dos mais diversos tipos: desde operações de aeroportos sendo privatizados e se tornando caros até aumentos de combustível e de passagens, resultando em reclamações do público sobre preços altos".

A Tabela 1, demonstra, de forma resumida, os principais pontos apresentados pelos entrevistados em relação a análise SWOT.

Tabela 1: Análise SWOT da empresa

\begin{tabular}{ll}
\hline \multicolumn{1}{c}{ S. PONTOS FORTES } & \multicolumn{1}{c}{ W. PONTOS FRACOS } \\
\hline - tomadas de decisões rápidas & - escassez de mão-de-obra na região \\
- colaboradores orgulhosos da empresa & - escala (reduzida) \\
- custo baixo de mão-de-obra & - inexistência de programa fidelidade \\
- identificação com população do interior & - volatilidade da malha \\
- aviões econômicos & - dificuldade em rotas longas \\
\hline \multicolumn{1}{c}{ O. OPORTUNIDADES } & \multicolumn{1}{c}{ T. AMEAÇAS } \\
- crescimento do mercado regional & - concorrência elevada do mercado \\
\hline - incentivo estatal a regionalização & - entrada de novos concorrentes \\
\hline - ascensão da classe C & - alto custo do petróleo \\
\hline & - desvalorização cambial \\
- grandes eventos (copa, olimpíadas) & -privatização de aeroportos \\
\hline
\end{tabular}

Fonte: Elaborado pelos autores baseado nas respostas dos gestores 
Um dos gestores entrevistados, analisou que o mercado mudou drasticamente desde a entrada da Azul Linhas Aéreas no mercado brasileiro. Após a fusão Azul/Trip, as rotas do mercado regional deixaram de ser analisadas individualmente e começaram a ser pensadas de modo a se complementarem com as demais. Ele ilustra como a dinâmica do pricing na empresa foi afetada pelo novo concorrente:

Existem três grandes players no mercado, com uma nova companhia: a Azul. Com a compra da Trip pela Azul, foi mudada a estratégia. A Azul colocou uma estratégia nacional dentro do mercado regional, com ambas se complementando. Isso prejudicou os resultados de nossa empresa, pois o mercado antes era muito tático, com muitas especificidades e com pouca estratégia no sentido amplo. A Azul tem uma estratégia nacional. Isso diminuiu a volatilidade do mercado, porém trouxe os preços dos voos regionais para baixo. Hoje o mercado faz um trabalho mais macro, com mais estabilidade e previsibilidade.

O mesmo entrevistado destaca um fato que começou a ocorrer em diversas rotas domésticas: a concorrência ônibus versus avião. Antigamente impensável essa concorrência foi possibilitada pela ascensão da classe $\mathrm{C}$ e queda no preço médio das tarifas.

Ônibus e avião são concorrentes indiretos. Apesar de serem modais diferentes, a concorrência existe em diversas rotas, por exemplo Ribeirão - São Paulo. A Passaredo tem uma característica interessante que é olhar para diversos modais, em algumas rotas olhamos os preços da passagem de barco (norte do país), por exemplo, para determinar nossos preços. A queda da tarifa e o aumento do poder de compra abriu esse tipo de concorrência.

Outro gestor entrevistado destaca as mudanças estratégicas das empresas diante dos desafios impostos pela alta dos custos e margens apertadas no mercado doméstico. A maior empresa do país, Tam, buscou até agora suas margens em voos para o exterior, enquanto a Gol ainda procura uma saída.

Com o aumento recente da competição nas rotas domésticas e luta entre as empresas para atrair novos clientes, as margens caíram ou até mesmo ficaram negativas. $\mathrm{O}$ passageiro da classe $\mathrm{C}$ ainda não é rentável. Esse movimento causou uma mudança de estratégia na TAM, que passou a ganhar nos voos internacionais e tenta diminuir as perdas nos domésticos. Se você analisa o balanço da Tam, percebe que o dinheiro vem praticamente todo de voos para fora do país. Foi um movimento acertado, a meu ver. Já a Gol, que gastou milhões na compra da Varig apenas para ter slots e posicionamento da marca no exterior, opera atualmente poucos voos internacionais e vai demorar um pouco mais para colocar a nova estratégia em prática

\section{A PRECIFICAÇÃO NA EMPRESA}

Este tópico descreverá o processo de criação e decisão do preço final de uma passagem aérea em uma companhia de pequeno porte brasileira. Com base nas entrevistas concedidas, foi possível estruturar o processo e demonstrar de forma clara as decisões e os desafios por trás da formação dos preços.

A área de planejamento é responsável por avaliar a demanda de passageiros nas cidades, o potencial de crescimento, o mercado na rota, o perfil do passageiro, os gargalos dos aeroportos - sendo importante salientar que muitos aeroportos brasileiros apresentam restrições para diversos tipos de aviões - e a parte burocrática com estados, municípios e ANAC. Após decidirem por certa rota, são feitos todos 
os cálculos de custo e gastos, simulações de cenários e finalmente início da estruturação do processo de operação.

$\mathrm{Na}$ área de Revenue Management, elabora-se uma tabela com diversas classes tarifárias e o preço disponível para cada classe. Esse trabalho é chamado dentro da empresa de pricing, e o responsável pela criação e manutenção das tabelas é um analista de pricing. Um dos entrevistados foi o gerente da área, que explicou que a base é a classe tarifária L, classe onde ocorre o break-even do voo. As classes acima expressam então margem operacional positiva e as classes abaixo margem operacional negativa.

Um dos entrevistados, que trabalhou como analista de precificação na Passaredo Linhas Aéreas e posteriormente trabalhou em outra empresa de grande porte do setor, também destacou a importância dos preços para as companhias aéreas. Na sua visão, as duas áreas mais importantes nesse tipo de empresa são o planejamento e o revenue.

Quando eu trabalhei na empresa maior, os diretores nos falavam que as duas áreas mais importantes da empresa era o Revenue e o Planejamento, pois eram nessas áreas que eram geradas todas as receitas. A demanda e a oferta eram responsabilidade de Revenue e Planejamento.

A resposta de ambos entrevistados em relação a importância da precificação e a função da precificação para as empesas foi muito similar. Para eles, o objetivo principal é acertar o preço para o cliente certo, no momento certo. Assim, é possível otimizar e segmentar seus clientes através dos preços. Os indicadores mais comuns do setor aéreo para verificar o desempenho de uma empresa são o ASK (Available Seat Kilometre), que reflete a capacidade da empresa de ofertar assentos por quilômetro transportado, o CASK (Cost of Available Seat Kilometre), que reflete o indicador de custos operacionais por assentos, o RASK (Revenue of Available Seat Kilometre), que reflete a receita por passageiros transportados por quilometro e o Yield, valor pago por passageiro por cada um quilômetro viajado.

Com a tabela de preços já feita pelo pricing, os dados são inseridos no sistema de vendas da empresa e ficam disponíveis para o analista de Revenue. O principal objetivo dos analistas de RM é distribuir os assentos conforme as classes tarifárias disponíveis de modo a maximizar a receita de um voo. $\mathrm{Na}$ aviação, quanto maior o RASK de um voo melhor. Um analista pode escolher vender apenas $50 \%$ da capacidade de um avião a preços elevados ou vender todos os assentos - em caso de demanda - a preços baixos. A estratégia utilizada pelos analistas vai depender da estratégia da empresa, decisão do gerente de $\mathrm{RM}$ e finalmente uma análise mais fina realizada por eles próprios.

Os analistas de voo escolhem o preço final a partir do inventário. Ele pode decidir colocar 15 promocionais porque o voo está ruim ou nenhuma promocional em um bom voo. Basicamente o analista utiliza o CASK, ocupação média da empresa por sazonalidade, dia da semana e tipo de voo, mas o principal é o CASK. O segundo é o desempenho histórico do voo. Isso é possível devido a informações passadas pelo planejamento. Escolhe-se então uma tarifa intermediaria, e com o Infare (software de análise de pricing), olhamos a concorrência, analisamos custos e desempenho do voo e então o analista tem autonomia para decidir o preço final. Ele é cobrado pelo resultado dos seus voos. Bases históricas são fundamentais para precificação.

Conforme a rota amadurece ao longo do tempo e gera seu histórico, o analista passa a contar com dados para análise e comparação que os auxiliam a balizar os preços, além de desenvolver um conhecimento natural sobre a performance do voo. Com um mercado sendo disputado passageiro a 
passageiro pelas empresas, muitas vezes os analistas decidem por preços que não vão trazer margem operacional positiva para a empresa, mas sim diminuir o prejuízo da operação. Segundo os entrevistados, caso seu custo por passageiro seja de R $\$ 100,00$ em um trecho com 100\% de ocupação e o mercado esteja oferecendo passagens a $\mathrm{R} \$ 50,00$, o analista vai igualar o mercado mesmo sabendo do prejuízo. Caso contrário, há risco do avião sair vazio.

Para os entrevistados não há alternativas para precificação a não ser usar o RM. As desvantagens seriam os custos de implementação e a dificuldade em encontrar mão de obra especializada, principalmente em cidades do interior. A maior vantagem é maximizar a receita e sobreviver em meio a um ambiente supercompetitivo.

\section{CONCLUSÃO}

O setor de aviação no Brasil passou nas últimas décadas por um intenso processo de transformação. Além do impressionante aumento do número de passageiros transportados, a estrutura competitiva do mercado mudou radicalmente. Do início dos anos 1990 até hoje, o mercado assistiu a falências de ícones nacionais (caso Varig), passou por reestruturações gerenciais após a fundação da Gol e, principalmente, ampliou o portfólio de clientes atendidos, passando a oferecer serviços a um número maior de passageiros. Concomitantemente, surgiram novos concorrentes (Avianca e Azul), dispostos a explorar mercados subutilizados o oferecer maior valor aos clientes.

Apesar de toda e evolução vista até aqui, algo vem assustando os acionistas e sócios das companhias aéreas brasileiras: balanços negativos em diversos anos fiscais. Com o interesse em investigar a influência do mercado sobre os preços de passagens aéreas, que são responsáveis por grande parte da receita, foi pesquisado quais são os tipos de precificação encontrados em uma companhia aérea de pequeno porte e que sofre as pressões dos concorrentes maiores, quais as principais alternativas de gestão de preços e as dificuldades em se rentabilizar um voo.

Os resultados desses estudos mostraram que esta empresa de pequeno porte determina seus preços majoritariamente baseando-se em seus concorrentes, o que as deixam sujeitas a operar com preços que nem sempre superam os custos em diversas rotas. No caso de rotas em que a empresa pesquisada não compete diretamente com nenhuma outra, os preços são baseados no custo, o que implica maior preço médio por trecho e maiores chances de margem operacional positiva.

A análise do trabalho mostra que existem diversas alternativas de precificação para as empresas, mais especificamente as de pequeno porte. A principal ferramenta para o controle e gerenciamento dos preços é o Revenue Management ou Yield Management, que atualmente é amplamente utilizado no mercado. Através dele, é possível utilizar diferentes estratégias com o objetivo de maximizar as receitas de um voo. As entrevistas mostraram que o mais importante para um gerenciamento de preço bem sucedido é uma boa base de dados com histórico de voos e capacidade de análise rápida e ajustes constantes. Os entrevistados foram unanimes em dizer que Revenue Management busca atender a ideia de preço certo, na hora certa, para o cliente correto.

Ao final, foi pesquisada as dificuldades e vantagens do modelo. O que foi concluído é que operar no mercado de aviação sem uma área de Revenue Management bem desenvolvida coloca em risco toda a operação e sobrevivência de empresas do setor. Ainda que as técnicas de precificação sejam bem conhecidas no setor, a complexidade das decisões e a necessidade de uma equipe específica torna bastante difícil o gerenciamento de preços por pequenas empresas. A precificação adequada, por outro lado, traz custos elevados e existe dificuldade em se encontrar mão-de-obra qualificada.

Nucleus,v.12,n.2,out.2015 
Em suma, a empresa estudada mostrou que o gerenciamento de preço do mercado tem uma relação complexa de testar o limite dos clientes ( qual é o máximo que estão dispostos a pagar pelo produto) com a inclusão da variável custos, havendo uma alternância entre o peso de importância de ambas.

O trabalho analisou de forma objetiva a precificação em uma pequena empresa do setor aéreo brasileiro e seus impactos. Os resultados alcançados possibilitam entender as dificuldades e as estratégias de precificação de uma pequena empresa aérea dentro do setor. $O$ trabalho poderá ser utilizado como base para novos estudos referentes ao tema, tendo em vista a escassez de material na bibliografia. Uma limitação importante é que o trabalho é baseado nas percepções dos entrevistados, que, apesar de serem tomadores de decisões da empresa, ainda assim são percepções não baseadas em dados quantitativos.

\section{REFERÊNCIAS}

ABEAR- Associação brasileira das Empresas Aéreas. Aviação Brasileira: Agenda 2020. São Paulo, 2013.

ANAC- Agencia Nacional de Aviação Civíl. Tarifas aéreas Domésticas. Brasília, 2010.

ANAC- Agencia Nacional de Aviação Civíl. Tarifas aéreas Domésticas. Brasília, 2011.

ANAC- Agencia Nacional de Aviação Civíl. Tarifas aéreas Domésticas.. Brasília, 2013.

ASSEF, R. Guia prático de formação de preços: aspectos mercadológicos, tributários e financeiros para pequenas e médias empresas. 5. ed. Rio de Janeiro: Campus, 1997.

AVLONITIS, G. J; INDOUNAS, K. A. Service Pricing: an empirical Investigation. Journal of Retailing and Consumer, v. 14, p. 83-94, 2007.

BAKOS, Y. Reducing Buyer Search Costs: Implications for Electronic Marketplaces. Management Science, v.43, p.1676- 92, 1997.

BERNARDI, L. A. Manual de formação de preço: políticas, estratégias e fundamentos. 4.ed.São Paulo: Atlas, 2010.BRAGA, R. M. M. Gestão da Gastronomia: custos, formação de preço, gerenciamento e planejamento de lucro. São Paulo: Senac, 2008.

COELHO, F. S. Formação estratégica de precificação: como maximizar o resultado das empresas. 2.ed. São Paulo; Atlas, 2009.

CHIANG, W.; CHEN, J.C.H.; XU, X. An overview of research on revenue management: current issues and future research. International Journal of Revenue Management, v. 1, n. 1, p. 97-128, 2006.

DUNLEAVY, H.; WESTERMANN, D. Future of Revenue Management: Future of airline revenue management. Journal of Revenue \& Pricing Management, v. 3, n.1, p. 380-383, 2005.

HINTERHUBER, A. Valor Preço. HSM Management, v. 78, p. 108-116, 2010.

HORNGREN, C. T; DATAR, S. M.; FOSTER, G. Contabilidade de custos: uma abordagem gerencial. 11. ed. São Paulo: Pearson-Prentice Hall, 2004. 
KAKINOFF, P. Entrevista ao programa Miriam Leitão. Globo News. Disponível em:

$<$ http://g1.globo.com/globo-news/miriam-leitao/videos/t/todos-os-videos/v/aereas-pedem-ajuda-aogoverno-mesmo-com-crescimento-do-setor/2836144/ >. Acesso em, 20 set. 2013.

KOTLER, P. Administração de Marketing. 10. ed. São Paulo: Prentice Hall, 2000.

KOTLER, P.; KELLER, K. L. Administração de Marketing. São Paulo: Pearson Prentice Hall, 2006.

KURTZ, D. L; CLOW, K. E. Services Marketing. Nova York: Witney, 1998.

LOVELOCK, C. H. Services Marketing. 3. ed. NJ: Prentice Hall, 1996.

LUDKE, M; ANDRE, M. E. D. A. A pesquisa em educação: abordagens qualitativas. 2. ed. São Paulo: EPU, 1986.

MANKIW, N. G. Principles of Microeconomics. 7. ed. Stamford: Cengage Learning, 2012.

MARTINS, E. Contabilidade de custos. 9.ed. São Paulo: Atlas, 2008.

MARTINS, G. A; LINTZ; A. Guia para elaboração de monografias e trabalhos. São Paulo: Atlas, 2000.

MENDES, J. T. G. Economia: fundamentos e aplicações. 2. Ed. São Paulo: Pearson, 2009.

MINTZBERG, H.; QUINN, J. B. O Processo da Estratégia. 3. ed. Porto Alegre: Bookman, 2001.

MOTTA, F. G. Fatores Condicionantes na adoção de métodos de custeio em pequenas empresas: estudo multicasos em empresas do setor metal-mecânico de São Carlos/SP. São Paulo, USP, 2000. Dissertação de Mestrado. Universidade de São Paulo.

NAGLE, T, T; HOLDEN, R. K. Estratégia e táticas de preço. 3.ed. São Paulo: Pearson Prentice Hall, 2005.

NETESSINE, S.; SHUMSKY, R. Introduction to the Theory and Practice of Yield Management, Transactions on Education, v.3 n. 1, 2002.

PASSARELLI, J.; BOMFIM, E. A. Orçamento empresarial: como elaborar. São Paulo: IOB, 2008.

PRADO, R. M. R. Templo do Oriente: proposta de adequação entre preço e posicionamento. Porto Alegre: UFRGS, 2009.

SANTOS, J. J. Fundamentos de custos para formação de preço e do lucro. 5. ed. São Paulo: Atlas, 2005.

SARTORI, E. Gestão de Preços: estratégia e flexibilização de preços, fidelização de clientes e aumento de rentabilidade. São Paulo: Atlas, 2004.

TALLURY, K.; RYZIN, G. J. V. The theory and practice of revenue management. Nova York: Springer Science, 2004.

WERNKE, R. Gestão de custos no comércio varejista. Curitiba: Juruá, 2011.

YIN, R. K. Estudo de Caso: planejamento e métodos. 2. ed. Porto Alegre: Bookman, 2001.

ZORNIG, F. Mais obstáculos: custo e aversão a risco. HSM Management, v. 78, p. 115, 2010. 